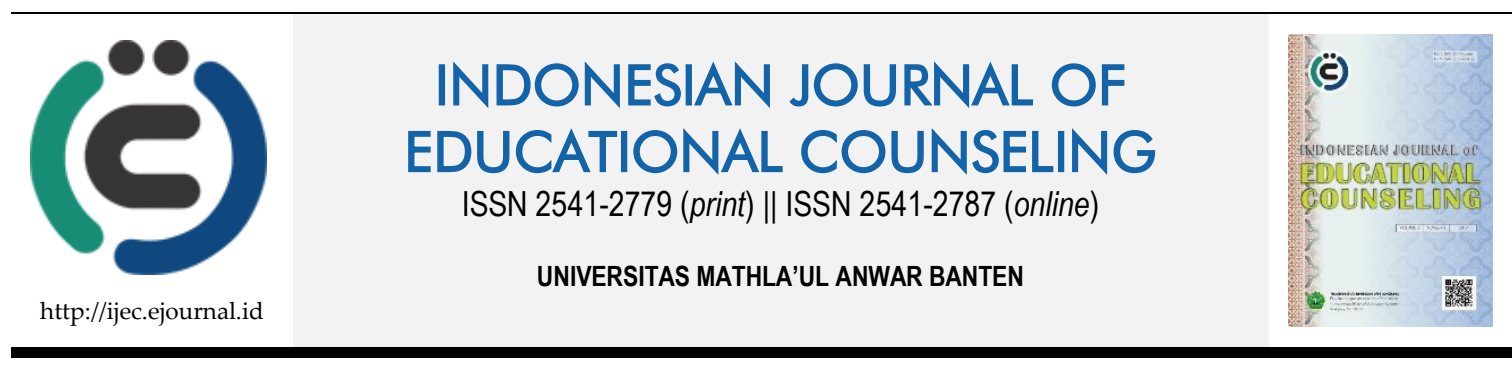

Research Based Article

\title{
Self-efficacy dan Burnout Akademik pada Mahasiswa yang Bekerja
}

\author{
Septriyan Orpina ${ }^{1}$, Sowanya Ardi Prahara ${ }^{2}$ \\ 1, 2 Universitas Mercu Buana Yogyakarta
}

\begin{tabular}{ll}
\hline Article History & ABSTRACT \\
\hline Received: 17.04 .2019 & SELF-EFFICACY AND ACADEMIC BURNOUT FOR WORKING STUDENTS. \\
Received in revised form: & Academic burnout refers to stress, burden or other psychological factors \\
16.06.2019 & because the learning process is followed by students so that it shows the state \\
Accepted: 02.07 .2019 & of emotional fatigue, tendency to depersonalization, and feeling of low personal \\
Available online: 22.07 .2019 & achievement. There are individual factors that can affect burnout; one of the \\
& individual factors that can influence academic burnout is academic self-efficacy. \\
& This study aims to determine the relationship between academic self-efficacy \\
& and academic burnout in working students. Based on the results of research \\
& and discussion, it can be concluded that there is a negative relationship between \\
& academic self-efficacy and academic burnout on students who work. This \\
& means that the higher academic self-efficacy, the lower academic burnout in \\
& working students, conversely the lower of Academic self-efficacy, the higher \\
& academic burnout in working students.
\end{tabular}

KEYWORDS: Academic Burnout, Academic Self-efficacy.

DOI: $10.30653 / 001.201932 .93$

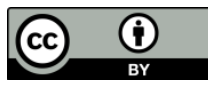

This is an open access article distributed under the terms of the Creative Commons Attribution 4.0 International License, which permits unrestricted use, distribution, and reproduction in any medium, provided the original work is properly cited. (c) 2019 Septriyan Orpina, Sowanya Ardi Prahara.

\section{PENDAHULUAN}

Pengertian "mahasiswa" menurut Kamus Besar Bahasa Indonesia (KBBI) adalah siswa yang belajar di Perguruan Tinggi (Depdiknas, 2005). Mahasiswa adalah golongan intelektual yang sedang menjalani pendidikan di perguruan tinggi dan diharapkan nantinya mampu bertindak sebagai pemimpin masyarakat, negara ataupun di dunia kerja (Wijaya, 2016). Kesibukan mahasiswa tidak terbatas hanya belajar di kampus saja, tetapi juga bekerja atau berwirausaha di luar kampus (Octavia \& Nugraha, 2013).

Kebutuhan akan hidup yang kian meningkat pula membuat mahasiswa harus mencari cara untuk mampu mencukupi kebutuhannya untuk pendidikan dan juga untuk biaya hidupnya. Beberapa mahasiswa mencari jalan keluar dengan cara bekerja. Banyak ditemukan fenomena peran ganda mahasiswa, yaitu kuliah sambil bekerja (Mardelina \& Muhson, 2017). Umumnya mahasiswa akan memilih bekerja dengan sistem kontrak

${ }^{1}$ Corresponding author's address: Program Studi Psikologi, Universitas Mercu Buana Yogyakarta; Jl. Ringroad Utara, Condong Catur, Sleman,

Yogyakarta; Email: septriyanorpina @ yahoo.co.id 
dalam jangka pendek (shortterm contracts) dan kerja paruh waktu (parttime jobs) (Van der Meer \& Wielers, 2001). Mahasiswa yang bekerja adalah individu yang menuntut ilmu pada jenjang perguruan tinggi dan berstatus aktif yang juga menjalankan usaha atau sedang berusaha mengerjakan suatu tugas yang diakhiri buah karya yang dapat dinikmati oleh orang yang bersangkutan (Dudija (2012).

Data dari National Center for Education Statistics (NCES) menyebutkan bahwa pada tahun 2007 sebanyak 40\% mahasiswa bekerja lebih dari 20 jam per minggu (Planty et al., dalam Dadgar, 2012). Mahasiswa yang bekerja harus dapat membagi waktu dan tanggung jawab terhadap komitmen dari kedua aktivitas tersebut. Hal inilah yang membuat mahasiswa menghabiskan sebagian waktu, energi serta tenaga, ataupun pikirannya untuk bekerja(Mardelina \& Muhson, 2017). Kondisi tersebut membuat mahasiswa kesulitan dalam mengatur atau membagi waktu antara bekerja dan kuliah, sehingga aktivitas mahasiswa bertambah dan cenderung mengabaikan tugasnya sebagai seorang mahasiswa untuk belajar serta mengerjakan tugas-tugas yang diberikan oleh dosen.Maka mahasiswa tersebut harus dapat membagi waktu dan konsentrasi serta bertanggung jawab terhadap komitmen dari kedua aktivitas tersebut. Hal ini membuat mahasiswa menghabiskan banyak waktu, energi serta tenaga untuk bekerja (Mardelina \& Muhson, 2017).

Aktivitas kuliah sambil bekerja menuntut mahasiswa untuk dapat menyeimbangkan antara aktivitas dalam bekerja dan kuliah yang dijalankan secara bersamaan. Apabila mahasiswa tidak dapat mengatur aktivitas akademik dan kerja dengan baik, maka akan ada salah satu aktivitas yang dikorbankan (Octavia \& Nugraha, 2013). Menurut Rice dan Dolgin (dalam Octavia \& Nugraha, 2013), ada dua pandangan mengenai kuliah sambil bekerja. Pandangan pertama, kuliah sambil bekerja akan menjadi hal yang buruk apabila memberikan jarak antara mahasiswa dengan kegiatan penting lainnya, seperti aktivitas perkuliahan dan waktu dengan keluarga. Pandangan kedua, kuliah sambil bekerja adalah hal yang baik apabila dijalankan dalam dosis yang kecil, karena terlalu banyak bekerja akan sangat beresiko bagi peran individu tersebut sebagai mahasiswa. Misalnya dalam sebuah permasalahan yang disampaikan oleh Kaho (2015) bahwa mahasiswa yang bekerja ternyata memiliki risiko lebih besar untuk memiliki masalah mental dalam dirinya. Adapun permasalahan lain yang dapat memberikan dampak buruk apabila mahasiswaterlalu sibuk bekerja, dimana kuliah sambil bekerja dapat menjadi salah satu faktor penghambat lulus kuliah (Priyatna, 2012).

Berdasarkan permasalahan di atas dapat diketahui bahwa kuliah sambil bekerja dapat memberikan permasalahan bagi yang menjalaninya. Arlinkasari dan Akmal (2017) mengatakan bahwa apabila mahasiswa tidak mampu menangani permasalahan di perkuliahan dan pekerjaan secara efisien maka akan membuat mahasiswa rentan terhadap berbagai permasalahan yang dapat memberikan dampak buruk. Salah satu permasalahannya yaitu burnout.Burnout dalam bidang akademik disebut academic burnout (Schaufeli, Martínez, Pinto, Salanova, \& Barker, 2002).

Academic burnout mengacu pada stres, beban atau faktor psikologis lainnya karena proses pembelajaran yang diikuti mahasiswa sehingga menunjukkan keadaan kelelahan emosional, kecenderungan untuk depersonalisasi, dan perasaan prestasi pribadi yang rendah (Yang, 2004). Hal ini sejalan dengan Rad, Shomoossi, Rakhshani, dan Sabzevari (2017) yang mendefinisikan academic burnout sebagai kurangnya minat seseorang dalam memenuhi tugas, rendahnya motivasi, dan kelelahan karena persyaratan pendidikan, 
sehingga munculnya perasaan yang tidak diinginkan dan perasaan tidak efisien. Dimensi dari academic burnout ada tiga, yaitu kelelahan emosional, disebabkan oleh tuntutan emosional dan psikologis yang berlebih dan biasanya berdampingan dengan perasaan frustasi dan ketegangan (Yang, 2004). Keengganan untuk studi atau sinisme, mengacu kepada ketidakpekaan atau sikap sinis terhadap pekerjaan yang sedang dihadapi. Sinisme juga dapat didefinisikan sebagai sikap apatis atau ketidakpedulian mahasiswa terhadap pekerjaan kuliah, tugas, dan tanggung jawab.Dan mengurangnya keinginan untuk berprestasi, berkurangnya keinginan untuk berprestasi terjadi ketika seseorang menampilkan kecenderungan untuk mengevaluasi diri sendiri negatif, sebuah penurunan perasaan kompetensi kerja, dan peningkatan perasaan inefficacy.

Tingkat academic burnout pada mahasiswa pun beragam. Berdasarkan data yang dipaparkan oleh Rad et al. (2017) bahwa di China terdapat 86,6\% mahasiswa mengalami stres akademik parah hingga menyebabkan academic burnout, sementara di Iran, mahasiswa kedokteran yang mengalami academic burnout sebanyak $76,8 \%$ dan stres berat sebanyak $71,7 \%$ yang disebabkan karena kekhawatiran tentang masa depan, khawatir melukai pasien, ketidakmampuan dalam melakukan teknis medis dan harapan yang tinggi dari keluarga. Di Eropa, sebanyak 1.702 mahasiswa keperawatan mengalami academic burnout, dimana mahasiswa merasa kurang mampu dalam mengerjakan tugas mahasiswa dan memiliki kecenderungan untuk berhenti bekerja. Mahasiswa Ilmu Manajerial di Serbia yang mengalami academic burnout sebanyak 54,4\%. Pada tahun 2009 data academic burnout yang terkait dengan studi di kalangan mahasiswa Finlandia yang dikumpulkan melalui survei Nasional dari 9 universitas di Finlandia, ditemukan bahwa $45 \%$ dari semua responden memiliki risiko mengalami peningkatan academic burnout, sementara sebanyak $19 \%$ responden lainnya memiliki risiko yang jelas untuk mengalami peningkatan academic burnout.

Hal ini diperkuat dengan wawancara yang dilakukan peneliti pada 26-27 Maret 2018 kepada 10 mahasiswa yang bekerja. Hasil wawancara menunjukkan bahwa mahasiswa memiliki perasaan lelah secara fisik maupun mental terhadap rutinitasnya yang padat seperti harus berangkat kuliah setelah seharian bekerja, mahasiswa merasa tidak dapat mengontrol perasaan emosionalnya, sehingga merasa kurang peduli terhadap orang lain dan dapat meluapkan emosinya kepada orang lain, mahasiswa mengatakan ingin meninggalkan aktivitas kuliah yang dijalaninya karena mahasiswa merasa berat dengan aktivitasnya yang berlebih sehingga ingin memilih salah satu dari rutinitasnya, mahasiswa tersebut juga mengatakan bahwa terkadang perkuliahan menambah beban pekerjaannya, kemudian mahasiswa menyatakan bahwa mahasiswa merasa terbebani oleh tugas-tugas yang diberikan oleh dosen dan terkadang merasa tidak mampu menyelesaikan tugas-tugasnya sehingga tidak mengumpulkan tugas yang diberikan oleh dosen.

Berdasarkan hasil wawancara di atas dapat disimpulkan bahwa sebanyak enam dari 10 orang mahasiswa memiliki masalah academic burnout. Hal tersebut ditunjukkan dengan perilaku dari dimensi kelelahan emosional, yaitu keenam mahasiswa tersebut memiliki perasaan lelah secara fisik maupun mental terhadap rutinitasnya yang padat seperti harus berangkat kuliah setelah seharian bekerja, bahkan keenam mahasiswa tersebut merasa tidak dapat mengontrol perasaan emosionalnya sehingga merasa kurang peduli terhadap orang lain dan dapat meluapkan emosinya kepada orang lain. Pada dimensi keengganan untuk studi atau sinisme, keenam mahasiswa tersebut mengatakan ingin meninggalkan 
aktivitas kuliah yang dijalaninya karena mahasiswa merasa berat dengan aktivitasnya yang berlebih sehingga ingin memilih salah satu dari rutinitasnya, dan keenam mahasiswa tersebut juga mengatakan bahwa terkadang perkuliahan menambah beban pekerjaannya. Kemudian pada dimensi mengurangnya keinginan untuk berprestasi, keenam mahasiswa tersebut menyatakan bahwa mahasiswa merasa terbebani oleh tugastugas yang diberikan oleh dosen dan terkadang merasa tidak mampu menyelesaikan tugas-tugasnya sehingga tidak mengumpulkan tugas yang diberikan oleh dosen.

Terlepas dari prioritas mahasiswa yaitu kuliah atau kerja, mahasiswa yang bekerja tetap harus mempertahankan prestasi akademis, menyelesaikan pendidikannya, dan memperoleh manfaat dari pendidikan yang dijalaninya (Orszag, Orszag, \& Whitmore, 2001). Maka mahasiswa tersebut harus dapat membagi waktu dan konsentrasi serta bertanggung jawab terhadap komitmen dari kedua aktivitas tersebut.

Cordes dan Dougherty (dalam Law, 2007) menyatakan bahwa burnout pada individu berhubungan dengan kemunduran hubungan interpersonal, dan pengembangan perilaku negatif yang dapat merusak individu yang bersangkutan. Mahasiswa yang mengalami academic burnout akan melewatkan kelas (ketidakhadiran), tidak mengerjakan tugas dengan baik, dan mendapat hasil ujian yang buruk hingga akhirnya berpotensi untuk dikeluarkan dari perguruan tinggi (Arlinkasari \& Akmal, 2017).

Pada beberapa penelitian, academic burnout memiliki berbagai dampak. Pada penelitian yang dilakukan oleh Rad et al. (2017) menunjukkan adanya hubungan negatif yang signifikan antara academic burnoutdengan psychological capital pada mahasiswa jurusan kesehatan di Iran. Semakin tinggi academic burnout maka semakin rendah psychological capital, dan sebaliknya. Selain itu, penelitian yang dilakukan oleh Ugwu, Onyishi, dan Tyoyima (2013) menunjukkan adanya hubungan yang signifikan antara academic burnout dengan academic engagement pada mahasiswa di Universitas Nigeria. Semakin tinggi academic burnout maka semakin buruk mahasiswa menangani berbagai masalah akademiknya, dan sebaliknya. Berdasarkan kedua penelitian di atas, dapat diketahui bahwa mahasiswa yang memiliki tingkat academic burnouttinggi, rentan memiliki psychological capital dan academic engagement yang rendah.

Burnout terdiri dari dua faktor (Maslach, Schaufeli, \& Leiter, 2001), yaitu: 1) Faktor situasional, pada faktor ini terdapat karakteristik pekerjaan (keanekaragaman keterampilan, identitas tugas, arti tugas, otonomi dan umpan balik), karakteristik jabatan, dan karakteristik organisasi; dan 2) Faktor individual, faktor ini meliputi karakteristik demografik (jenis kelamin, latar belakang etnis, usia, status perkawinan, latar belakang pendidikan), karakeristik kepribadian (konsep diri rendah, kebutuhan diri yang terlalu besar, kemampuan yang rendah dalam mengendalikan emosi, locus of control eksternal, introvert, keyakinan akan kemampuan diri) dan sikap kerja.

Berdasarkan faktor-faktor di atas, terdapat faktor individual yang dapat mempengaruhi burnout. Salah satu faktor individual yang dapat menyebabkan burnout adalah keyakinan dalam kemampuan diri. Keyakinan dalam kemampuan diri oleh Bandura disebut sebagai self-efficacy atau efikasi diri (Rustika, 2016). Self-efficacy pada dasarnya bersifat spesifik, dalam penelitian ini self-efficacy yang dimaksud adalah academic self-efficacy. Peneliti memilih faktor academic self-efficacy untuk dijadikan sebagai variabel bebas dalam penelitian ini karena mahasiswa dengan self-efficacy yang tinggi memiliki fleksibilitas dalam mencari solusi terkait masalah perkuliahan yang mahasiswa hadapi, 
menetapkan aspirasi yang lebih tinggi pada pencapaian akademiknya, dan memiliki performa yang lebih baik dibanding mahasiswa dengan self-efficacy rendah (Chemers, $\mathrm{Hu}$, \& Garcia, 2001).

Hasil wawancara yang dilakukan peneliti tanggal 27 Maret 2018 kepada 10 mahasiswa yang bekerja menunjukkan bahwa mereka memiliki kecenderungan keyakinan yang kurang memadai dalam menyelesaikan tugas-tugas di perkuliahan ataupun pekerjaannya, mahasiswa yang bekerja juga mengaku bahwa mahasiswa kurang memiliki performa yang baik saat mengikuti perkuliahan karena sudah lelah bekerja seharian, dan para mahasiswa mengaku bahwa apabila ada permasalahan akademik mahasiswa merasa tidak yakin dapat menemukan solusi yang tepat untuk menyelesaikan permasalahannya. Berdasarkan hasil wawancara terdapat enam dari 10 orang mahasiswa yang bekerja memiliki academic self-efficacy yang kurang memadai. Hal tersebut ditunjukkan dengan dimensi interaction at school, mahasiswa mengaku kadang-kadang tidak berani berpartisipasi dalam diskusi di kelas, merasa kehilangan kepercayaan diri, dan merasa dirinya tidak mampu untuk dapat bergaul di lingkungan kampus dengan baik.Pada dimensi academic performance out of class, mahasiswa mengaku merasa sulit untuk menyelesaikan tugas tepat waktu, merasa kesulitan dalam mengatasi permasalahan yang ada di luar perkuliahan, dan mahasiswa tidak mampu mengembangkan potensi dirinya dengan baik.Pada dimensi academic performance in class, mahasiswa mengaku mengalami kesulitan dalam mengatur kedua aktivitasnya yaitu kuliah dan bekerja, merasa mudah menyerah, dan beberapa dari mahasiswa mengaku sering menghindari permasalahan karena merasa mampu untuk menyelesaikannya. Kemudian pada dimensi managing work, family, and school, mahasiswa mengaku kesulitan dalam membagi waktu kerja, kuliah, dan keluarga karena disibukkan dengan beberapa aktivitasnya dan mahasiswa kadang-kadang merasa tidak memiliki performa yang penuh saat beraktivitas.

Academic self-efficacy mengacu pada keyakinan mahasiswa terhadap kemampuan mahasiswa dalam melaksanakan tugas-tugas akademik seperti mempersiapkan diri untuk ujian dan menyusun makalah (Zajacova, Lynch, \& Espenshade, 2005). Terdapat empat dimensi dari academic self-efficacy (Zajacova et al., 2005), yaitu: 1) Interaction at school. Dimensi ini merupakan keyakinan tentang kemampuan diri untuk berinteraksi dengan orang-orang yang terlibat di perguruan tinggi; 2) Academic performance out of class. Keyakinan mahasiswa dalam menampilkan kemampuan dirinya selama di luar perkuliahan; 3) Academic performance in class. Keyakinan mahasiswa dalam menampilkan kemampuan dirinya ketika mengikuti perkuliahan; dan 4) Managing work, family, and school. Keyakinan mahasiswa dalam mengatur pekerjaan, keluarga, dan perkuliahan secara efektif.

Academic burnout mengacu pada stres, beban atau faktor psikologis lainnya, karena proses pembelajaran yang diikuti mahasiswa, sehingga menunjukkan keadaan kelelahan emosional, kecenderungan untuk depersonalisasi, dan perasaan prestasi pribadi yang rendah (Yang, 2004). Academic burnout berkorelasi dengan sejumlah variabel psikologis, salah satunya adalah academic self-efficacy. Rahmati (dalam Arlinkasari \& Akmal, 2017) menyebut bahwa mahasiswa yang tidak memiliki academic self-efficacy yang memadai menjadi rentan terhadap academic burnout dan kurang memiliki kemampuan untuk beradaptasi. Ugwu et al. (2013) menyarankan agar mahasiswa memiliki self-efficacy yang memadai, sehingga terlindung dari potensi academic burnout. 
Mahasiswa dengan academic self-efficacy yang baik dapat menghasilkan dan mampu menguji berbagai alternatif tindakan ketika mahasiswa tidak mencapai keberhasilan pada awalnya. Mahasiswa dengan tingkat academic self-efficacy yang tinggi ketika menghadapi masalah akademik tidak akan mudah menyerah dan mencoba untuk menemukan solusi yang tepat untuk memecahkan masalah mahasiswa (Charkhabi et al. dalam Arlinkasari \& Akmal, 2017). Sebaliknya mahasiswa dengan academic self-efficacy yang rendah cenderung menilai masalah lebih sulit daripada yang sebenarnya, lebih rentan terhadap stres, depresi dan memiliki kemampuan pemecahan masalah yang kurang baik. Hal tersebut menunjukkan bahwa academic self-efficacy ikut berperan dalam menurunkan academic burnout pada mahasiswa (Rahmati dalam Arlinkasari \& Akmal, 2017). Berdasarkan uraian di atas, peneliti mengajukan sebuah rumusan permasalahan apakah ada hubungan antara academic self-efficacy dengan academic burnout pada mahasiswa yang bekerja?

\section{METODE}

Subjek dalam penelitian ini adalah mahasiswa yang kuliah sambil bekerja. Pengambilan subjek dalam penelitian ini menggunakan teknik purposive sampling. Jumlah subjek dalam penelitian ini sebanyak 60 subjek. Metode penyusunan skala dalam penelitian ini mengacu pada model likert.

Skala yang digunakan dalam penelitian ini adalah Skala Academic burnout dan Skala Academic Self-efficacy, dengan aitem-aitem skala yang hanya dibagi dalam satu kelompok saja, yaitu kelompok favourable. Bentuk skala yang digunakan adalah model skala likert dengan 4 alternatif jawaban yaitu: Sangat Sesuai (SS), Sesuai (S), Tidak Sesuai (TS), dan Sangat Tidak Sesuai (STS).

Skala Academic burnout terdiri dari 15 aitem dengan koefisien aitem-total (Rix) daya beda aitem bergerak dari rentang 0,250-0,630, sedangkan Skala Academic Self-efficacy terdiri dari 20 aitem dengan koefisien aitem-total (Rix) daya beda aitem bergerak dari rentang 0,355-0,749. Berdasarkan hasil perhitungan dari Skala Academic burnoutdiperoleh koefisien reliabilitas alpha $(\alpha)$ sebesar 0,828 dan Skala Academic Self-efficacy diperoleh koefisien reliabilitas alpha $(\alpha)$ sebesar 0.911 . Metode analisis data menggunakan teknik korelasi product moment. Keseluruhan data dianalisis menggunakan program analisis data.

\section{HASIL DAN PEMBAHASAN}

Yang (2004) menjelaskan mengenai dimensi yang terdapat dalam academic burnout yaitu kelelahan emosional, keengganan untuk studi atau sinisme, dan kurangnya keinginan untuk berprestasi. Academic burnout pada mahasiswa yang bekerja tidak terbentuk dengan sendirinya, namun ada beberapa faktor yang mempengaruhi academic burnout. Salah satu faktor yang dapat mempengaruhi academic burnout adalah self-efficacy. Konsep self-efficacy juga berlaku dalam konteks akademis, sehingga dapat disebut juga sebagai academic self-efficacy. Menurut Zajacova et al. (2005) academic self-efficacy mengacu pada keyakinan mahasiswa terhadap kemampuannya dalam melaksanakan tugas-tugas akademik seperti mempersiapkan diri untuk ujian dan menyusun makalah. Rahmati (dalam Arlinkasari \& Akmal, 2017) mengatakan bahwa mahasiswa yang tidak memiliki academic self-efficacy yang memadai menjadi rentan terhadap academic burnout dan kurang 
memiliki kemampuan untuk beradaptasi. Mahasiswa dengan academic self-efficacy yang baik dapat menghasilkan dan mampu menguji berbagai alternatif tindakan ketika mahasiswa tidak mencapai keberhasilan pada awalnya. Mahasiswa dengan tingkat academic self-efficacy yang tinggi ketika menghadapi masalah akademik tidak akan mudah menyerah dan mencoba untuk menemukan solusi yang tepat untuk memecahkan masalah mahasiswa (Charkhabi et al. dalam Arlinkasari \& Akmal, 2017). Sebaliknya mahasiswa dengan academic self-efficacy yang rendah cenderung menilai masalah lebih sulit daripada yang sebenarnya, lebih rentan terhadap stres, depresi dan memiliki kemampuan pemecahan masalah yang kurang baik. Hal tersebut menunjukkan bahwa academic self-efficacy ikut berperan dalam menurunkan academic burnout pada mahasiswa (Rahmati dalam Arlinkasari \& Akmal, 2017).

Hasil penelitian menunjukkan adanya hubungan negatif yang signifikan antara academic self-efficacy dengan academic burnout dengan nilai korelasi ( $\mathrm{rxy}$ ) sebesar $\mathrm{r}=-0.720$ dan $p=0.000$. Adanya korelasi tersebut membuktikan bahwa academic self-efficacy mempunyai peran penting terhadap academic burnout pada mahasiswa yang bekerja. Hal tersebut sesuai dengan hipotesis yang diajukan peneliti bahwa semakin tinggi academic self-efficacy maka akan semakin rendahacademic burnout padamahasiswa yang bekerja. Sebaliknya semakin rendah academic self-efficacy maka semakin rendah academic burnout yang dimilikimahasiswa yang bekerja. Academic self-efficacy merupakan suatu variabel yang memiliki sumbangan negatif terhadap academic burnout. Hasil penelitian ini mendukung penelitian sebelumnya yang dilakukan Arlinkasari dan Akmal (2017) yang menunjukkan bahwa terdapat hubungan yang negatif antara academic self-efficacy dengan academic burnout. Semakin tinggi academic self-efficacy maka semakin rendah academic burnout. Sebaliknya, semakin rendah academic self-efficacy maka semakin tinggi academic burnout. Adanya hubungan antara academic self-efficacy dengan academic burnout berarti setiap aspek academic self-efficacy memberikan sumbangan terhadap academic burnout pada mahasiswa yang bekerja.

Academic self-efficacy diartikan sebagai penilaian diri sendiri atas suatu kemampuan untuk mengatur dan melaksanakan kegiatan belajar untuk mencapai hasil prestasi berdasarkan jenis pendidikan yang ditentukan. Diterimanya hipotesis dalam penelitian ini diperoleh koefisien determinasi $\left(\mathrm{R}^{2}\right)$ sebesar 0.518 menunjukkan bahwa variabel academic self-efficacy pada mahasiswa yang bekerja memiliki konstribusi sebesar 51,8\% terhadap academic burnoutdan sisanya 48,2\% dipengaruhi oleh faktor situasional dan individual yang meliputi karakteristik demografik dan karakteristik kepribadian yang terdiri dari konsep diri, aktualisasi diri, kecerdasan emosi, locus of control, introvert, dan self-efficacy. Sedangkan hasil kategorisasi academic burnoutyaitu kategorisasi tinggi sebesar $0 \%$, kategori sedang sebesar $55 \%$, dan kategori rendah sebesar $45 \%$. Pada kategorisasi variabel academic self-efficacy yaitu kategorisasi tinggi sebesar 41,66\%, kategorisasi sedang sebesar 56,66\%, dan rendah sebesar 1,68\%. Hasil kategorisasi tersebut menunjukkan bahwa sebagian besar mahasiswa yang bekerja memiliki academic burnout yang cenderung rendah dan academic self-efficacy yang cenderung tinggi.

Menurut Zajacova et al. (2005) academic self-efficacy mengacu pada keyakinan mahasiswa terhadap kemampuan mahasiswa dalam melaksanakan tugas-tugas akademik seperti mempersiapkan diri untuk ujian dan menyusun makalah. Mahasiswa dengan academic self-efficacy yang baik dapat menghasilkan dan mampu menguji berbagai alternatif tindakan ketika mahasiswa tidak mencapai keberhasilan pada awalnya. 
Mahasiswa dengan tingkat academic self-efficacy yang tinggi ketika menghadapi masalah akademik tidak akan mudah menyerah dan mencoba untuk menemukan solusi yang tepat untuk memecahkan masalah mahasiswa (Charkhabi dkk., dalam Arlinkasari \& Akmal, 2017). Menurut Zajacova et al., (2005) ada empat dimensi dari academic self-efficacy, yaitu: (a) Interaction at school, (b) Academic performance out of class, (c) Academic performance in class, (d) Managing work, family, and school.

Dimensi interaction at school adalah dimensi yang membahas mengenai keyakinan individu tentang kemampuan diri untuk berinteraksi dengan orang-orang yang terlibat di perguruan tinggi (Zajacova et al., 2005). Individu dengan kemampuan interaction at school yang baik akan mampu untuk berinteraksi dengan orang-orang di perguruan tinggi, seperti berbicara dengan professor atau dosen saat berada di lingkungan kampus, dapat mencari pertolongan dan mencari informasi di kampus, mampu dan tidak malu untuk berbicara dengan staf kampus, berpartisipasi dalam diskusi kelas secara aktif, dan memahami peraturan di kampus dengan baik (Zajacova et al., 2005). Hal ini diperkuat dengan penuturan subjek di lapangan yaitusaat mengikuti proses perkuliahan subjek selalu berusaha untuk mengajukan pertanyaan kepada dosen dan mencoba untuk berpartisipasi dengan baik dalam diskusi kelas sehingga subjek dapat mendapatkan informasi yang dibutuhkan dengan baik. Subjek juga menuturkan bahwa subjek dapat berinteraksi dengan staf kampus untuk mendapatkan informasi mengenai peraturan kampus sehingga subjek dapat memahami peraturan yang ada di kampus dengan baik. Hal tersebut menunjukkan bahwa subjek mampu dan tidak menarik diri secara sosial dengan lingkungannya sehingga subjek tidak merasa frustasi di kampus dan tidak membuat kepedulian subjek pada orang lain berkurang walaupun subjek melakukan aktivitas di berbagai tempat yaitu seperti di tempat kerja dan di universitas.

Pada dimensi academic performance out of class mengacu pada keyakinan mahasiswa dalam menampilkan kemampuan dirinya selama di luar perkuliahan (Zajacova et al., 2005). Individu dengan kemampuan academic performance out of class yang baik akan menampilkan kemampuan dirinya dalam hal belajar secara mandiri, membaca dan fokus pada bacaan yang diperlukan, menuliskan makalah, menyelesaikan tugas tepat waktu, mempersiapkan ujian dengan baik, meningkatkan kemampuan dalam membaca dan menulis, meneliti makalah, dan memahami buku yang dipelajari (Zajacova et al., 2005). Sehingga mahasiswa yang memiliki academic performance out of class yang baik memiliki keyakinan yang tinggi dan selalu berusaha mengembangkan potensi diri secara maksimal serta menunjukan yang terbaik dari dirinya dibuktikan dengan sebuah pencapaian prestasi. Hal ini sangat mempengaruhi kesuksesan dalam belajar dan bekerja, dalam lingkungan keluarga, dan hubungan sosial dengan orang lain (Komara, 2016). Hal ini diperkuat dengan penuturan subjek di lapangan yang mengatakan bahwa subjek mampu untuk menyelesaikan tugas tepat waktu sesuai deadline dan subjek juga mampu menyelesaikan tugas laporan dengan baik sesuai dengan perintah dosen.Subjek juga menuturkan bahwa subjek selalu berusaha untuk mengatur diri seperti membuat jadwal untuk menyelesaikan tugas-tugas kuliah agar dapat terselesaikan dengan baik dan maksimal sehingga hal tersebut tidak membuat ketertarikan subjek terhadap perkuliahan berkurang walaupun kuliah sambil bekerja menguras pikiran dan tenaganya.Dengan mengatur diri, subjek tidak merasa mudah lelah sepulang dari mengikuti kelas perkuliahan walaupun ketika bangun di pagi hari subjek terkadang merasa letih ketika membayangkan tugas-tugas yang harus di hadapi pada hari tersebut di kelas. 
Dimensi academic performance in class adalah keyakinan mahasiswa dalam menampilkan dirinya ketika mengikuti perkuliahan (Zajacova et al., 2005). Individu dengan academic performance in class yang optimal akan menampilkan kemampuannya dalam mengerjakan ujian dengan baik, mengikuti beberapa ujian pada minggu yang sama, meraih peringkat yang diinginkan, dan mengikuti kelas yang dianggapnya berat dengan baik (Zajacova et al., 2005). Menurut Noble et al., (2008), academic performance in class yang optimal berhubungan dengan peningkatan hasil akademik, kehadiran di sekolah atau perguruan tinggi, perilaku prososial, keamanan sekolah atau perguruan tinggi dan kesehatan mental. Hal ini diperkuat dengan penuturan subjek di lapangan yang menyatakan bahwa subjekselalu berusaha untuk mengatur waktu belajar dalam mempersiapkan ujian dengan maksimal agar mampu mengerjakan ujian dengan baik sehingga subjek dapat meraih IPK yang ditargetkannya.Namun subjek juga menuturkan bahwa terkadang subjek kurang antusias dengan studinya karena kuliah sambil bekerja membuat pikirannya terbagi-bagi dan membuat subjek merasa terbebani dengan ujian di perkuliahan, namun hal tersebut tidak membuat subjek merasa bosan untuk mengikuti aktivitas di perkuliahan.

Dimensi yang terakhir yaitu dimensi managing work, family, and school. Dimensi ini membahas mengenai keyakinan mahasiswa dalam mengatur pekerjaan, keluarga, dan perkuliahan secara efektif (Zajacova et al., 2005). Menurut Fisher dkk. (dalam Wenno, 2018) managing work, family, and school merupakan hal yang dilakukan individu dalam membagi waktu baik di tempat kerja dan aktivitas lain di luar kerja yang di dalamnya terdapat individual behaviour dimana hal ini dapat menjadi sumber konflik pribadi dan menjadi sumber energi bagi diri sendiri. Individu yang memiliki managing work, family, and school yang baik dapat mengatur waktu dengan baik, dapat menyelesaikan tugas diperkuliahan dan pekerjaan tepat waktu, dapat mengatur waktu luang untuk keluarga, sehingga individu akan dapat bekerja dengan baik sesuai dengan tanggung jawab yang ada dan memiliki kedisiplinan dalam mengurus perkuliahan maupun pekerjaan (Wenno, 2018). Hal ini diperkuat dengan penuturan subjek di lapangan yang menyatakan bahwa subjekselalu berusaha untuk mampu mengatur segala hal dengan baik di berbagai aktivitas yang dilakukannya walaupun subjek kuliah sambil bekerja. Subjek berusaha untuk mengatur waktu dengan baik dan berusaha untuk meluangkan waktu belajar meskipun disibukkan dengan pekerjaan.Namun subjek juga menuturkan bahwa subjek terkadang merasa tidak mampu untuk mengerjakan tugas kuliah yang datang secara bersamaan karena subjek juga disibukkan dengan tugas pekerjaannya. Tugas-tugas yang datang secara bersamaan tersebut terkadang membuat subjek kurang bersemangat untuk mengerjakan tugasnya, dan hal tersebut membuat subjek pesimis untuk dapat menyelesaikan studinya tepat waktu.

\section{SIMPULAN}

Temuan penelitian menunjukkan bahwa terdapat hubungan yang negatif antara academic self-efficacy dengan academic burnout pada mahasiswa yang bekerja. Hal tersebut dapat dilihat dari koefisien korelasi $\left(\mathrm{r}_{\mathrm{xy}}\right)$ sebesar -0.720 dengan taraf signifikansi $\mathrm{p}=0.000$ $(\mathrm{p}<0,05)$ yang berarti ada hubungan negatif antara academic burnout dengan academic selfefficacy pada mahasiswa yang bekerja. Koefisien determinasi $\left(R^{2}\right)$ menunjukkan bahwa variabel academic self-efficacy memiliki kontribusi 51,8\% terhadap academic burnout dan sisanya $48,2 \%$ dipengaruhi oleh faktor lain yaitu seperti faktor situasional dan individual 
yang meliputi karakteristik demografik dan karakteristik kepribadian yang terdiri dari konsep diri, aktualisasi diri, kecerdasan emosi, locus of control, introvert, dan self-efficacy.

Penelitian ini dapat dijadikan sebagai acuan bagi para mahasiswa dalam mengatasi permasalahan akademik yang kerap dialami oleh mahasiswa yang bekerja, terutama yang berkaitan dengan faktor-faktor psikologis yang dapat memicu kemungkinan mahasiswa mengalami academic burnout. Penelitian ini juga dapat digunakan sebagai referensi untuk menyeimbangkan kemampuan mahasiswa yang bekerja dalam mengelola aktivitas dan meningkatkan keyakinan diri yang kuat dalam menyelesaikan pendidikan, hal tersebut dapat meningkatkan academic self-efficacy untuk menurunkan academic burnout pada mahasiswa yang bekerja. Bagi institusi pendidikan dapat memberikan pelatihan untuk mengembangkan academic self-efficacy pada mahasiswa yang bekerja guna melindungi mahasiswa dari potensi mengalami academic burnout selama menjalani perkuliahan. Sementara bagi dosen mata kuliah ataupun pembimbing akademik dapat meningkatkan kemampuan interaction at school, academic performance out of class, academic performance in class, dan managing work, family, and school pada mahasiswa, sehingga mahasiswa mampu meningkatkan academic self-efficacy yang dimiliki dan terhindar dari potensi mengalami academic burnout.

\section{REFERENSI}

Arlinkasari, F., \& Akmal, S. Z. (2017). Hubungan antara school engagement, academic selfefficacy dan academic burnout pada mahasiswa. Humanitas (Jurnal Psikologi), 1(2), 81-102. doi: 10.28932/humanitas.v1i2.418

Chemers, M. M., Hu, L. T., \& Garcia, B. F. (2001). Academic self-efficacy and first year college student performance and adjustment. Journal of Educational Psychology, 93(1), 55-64.

Dadgar, M. (2012). The academic consequences of employment for students enrolled in community college. CCRC working paper no. 46. New York: Community College Research Center, Columbia University.

Depdiknas. (2005). Kamus besar bahasa Indonesia (KBBI). Edisi III. Jakarta: Balai Pustaka.

Dudija, N. (2012). Perbedaan motivasi menyelesaikan skripsi antara mahasiswa yang bekerja dengan mahasiswa yang tidak bekerja. Humanitas: Indonesian Psychological Journal, 8(2), 196-206. doi: 10.26555/HUMANITAS.V8I2.464

Kaho, J, R. (2015). Hati-hati, mahasiswa yang bekerja bisa memiliki masalah mental. Retrieved March 20, 2018, from https://www.brilio.net/life/hati-hati-mahasiswa-yang-bekerjabisa-memiliki-masalah-mental-150730a.html.

Komara, I. B. (2016). Hubungan antara kepercayaan diri dengan prestasi belajar dan perencanaan karir siswa. Psikopedagogia Jurnal Bimbingan dan Konseling, 5(1), 33-42. doi: 10.12928/psikopedagogia.v5i1.4474 
Law, D. W. (2007). Exhaustion in university students and the effect of coursework involvement. Journal of American College Health, 55(4), 239-245. doi: 10.3200/JACH.55.4.239-245

Mardelina, E., \& Muhson, A. (2017). Mahasiswa bekerja dan dampaknya pada aktivitas belajar dan prestasi akademik. Jurnal Economia, 13(2), 201-209. doi: 10.21831/economia.v13i2.13239

Maslach, C., Schaufeli, W. B., \& Leiter, M. P. (2001). Job burnout. Annual Review of Psychology, 52, 397-422. doi: 10.1146/annurev.psych.52.1.397

Noble, T., McGrath, H., Wyatt, T., Carbines, R., Robb, L., \& International, E. (2008). Employment and workplace relations scoping study into approaches to student wellbeing. Final report. Seven, (November), 177. Brisbanne: Australian Catholic University (ACU).

Octavia, E., \& Nugraha, S. P. (2013). Hubungan antara adversity quotient dan work-study conflict pada mahasiswa yang bekerja. Psikologi Integratif, 1(1), 44-51.

Orszag, J. M., Orszag, P. R., \& Whitmore, D. M. (2001). Learning and earning: Working in college. Journal of Student Employment, 10(1), 1-19.

Priyatna, A. (2012). Inilah faktor penghambat lulus kuliah. Kompasiana. Retrieved March 20, 2018, from https://www.kompasiana.com/adryandrea/inilah-faktorpenghambat-lulus kuliah_550e3d24a33311bf2dba8016

Rad, M., Shomoossi, N., Rakhshani, M. H., \& Sabzevari, M. T. (2017). Psychological capital and academic burnout in students of clinical majors in Iran. Acta Facultatis Medicae Naissensis, 34(4), 311-319. doi: 10.1515/afmnai-2017-0035

Rustika, I. M. (2016). Efikasi Diri: Tinjauan Teori Albert Bandura. Buletin Psikologi, 20 (12), 18-25. https://doi.org/10.22146/bpsi.11945

Schaufeli, W. B., Martínez, I. M., Pinto, A. M., Salanova, M., \& Barker, A. B. (2002). Burnout and engagement in university students a cross-national study. Journal of CrossCultural Psychology, 33(5), 464-481. doi: 10.1177/0022022102033005003

Ugwu, F. O., Onyishi, I. E., \& Tyoyima, W. A. (2013). Exploring the relationships between academic burnout, selfefficacy and academic engagement among Nigerian college students. The African Symposium, 13(2), 37-45.

Van der Meer, P., \& Wielers, R. (2001). The increased labour market participation of Dutch students. Work, Employment and Society, 15(1), 55-71.

Wenno, M. W. (2018). Hubungan antara worklife balance dan kepuasan kerja pada karyawan di PT PLN Persero Area Ambon. Jurnal Maneksi,7(1), 47-54.

Wijaya, R, S. (2016). Perbandingan peneysuaian diri mahasiswa berkepribadian ekstrovert dan introvert. Jurnal Penelitian Tindakan Bimbingan dan Konseling, 2(2), 1-6. 
INDONESIAN JOURNAL OF EDUCATIONAL COUNSELING 2019, 3(2), 119-130

Wulan, D. A. N., \& Abdullah, S. M. (2014). Prokrastinasi akademik dalam penyelesaian skripsi. Jurnal Sosio-Humaniora, 5(1), 55-74.

Yang, H. J. (2004). Factors affecting student burnout and academic achievement in multiple enrollment programs in Taiwan's technical-vocational colleges. International Journal of Educational Development, 24(3), 283-301. doi: 10.1016/j.ijedudev.2003.12.001

Zajacova, A., Lynch, S. M., \& Espenshade, T. J. (2005). Self-efficacy, stress, and academic success in college. Research in higher education, 46(6), 677-706. doi: 10.1007/s11162-004$4139-\mathrm{z}$ 